\title{
Comparative Addictive Rating Scale
}

\author{
Clairmont Griffith and Bernice La France* \\ Howard University College of Medicine, USA
}

Submission: September 29, 2018; Published: October 24, 2018

*Corresponding author: Bernice La France, MSA, M.Ed., SLLA, ESL, Howard University College of Medicine, 2041 Georgia Ave. NW, Washington, D.C. 20060, USA; Tel: 202 865-6714; Email: bemore1576@gmail.com

\begin{abstract}
Use and addiction to various drugs such as alcohol, nicotine and opioids (heroin) have caught the attention of scholars and experts, and many studies have been directed to this area because of the effects of drug use and subsequent addiction. The global increase in the usage and abuse of illegal drugs both contribute and reflect international tensions, according to the National Institute on Drug Abuse [1] . Some of the causes of these tensions are obvious and they include reduced community and family cohesiveness, increased crime rates, political realignments, increased underemployment and unemployment, and social and economic marginalization. For instance, alcohol, nicotine and heroin cost the US government around $\$ 740$ billion annually in terms of crime, healthcare and lost productivity Degenhardt et al. [2]. Drug use is defined as the use of illegal drugs such as tobacco, heroin and cocaine while drug misuse refers to unhealthy or improper use of drug prescriptions. Addiction is defined as a chronic mental disorder that affects brain activities and is usually characterized by the user's inability to control the desire or need for the drug even when negative side-effects develop Hall, Carter \& Forlini [3]. Drug addicts strive to get and use the drug despite their harmful effects. Owing to the severity of the drug menace, scholars and experts have redirected their efforts and resources towards this issue. To categorize these drugs in terms of their addiction, five criteria are used because there is no single way of comparing the addictive scales of the illicit drugs. Drug use disorders were classified as severe, mild or moderate using the DSM diagnostic criteria. Nevertheless, these criteria are not conclusively since they do not permit a comparative rating of drugs according to their level of addiction.
\end{abstract}

However, using relevant research materials, this paper will primarily examine the scale of addiction for nicotine, alcohol, and opioids. This paper attempts to establish among the three drugs, which drug is over abused and more addictive than the others. To develop a comparative addiction rating scale for nicotine, opioids (heroin), and alcohol, this paper will consider the following key words:
1. Withdrawal
2. Tolerance
3. Reinforcement
4. Dependence
5. Intoxication

\section{Introduction}

Hasin and Grant [4] reason that the deteriorating living conditions have forced some individuals to result to drug and substance abuse, with the hope of finding consolation in these drugs. The rising cases of drug and substance use and abuse have created a drug menace among different countries and societies. There is an urgent need to address the drug menace to save the current and future generations before the situation blows out of hand and proportion.

There are varied misconceptions across the United States regarding drug and substance abuse and scale of addiction. For instance, a big number of people argue that addiction is a personal choice or is caused by criminal or deviant behaviors. Abuse [5] notes that these misconceptions have created a lot of stigmatization on people struggling with addiction, and this is making it quite hard for the affected people to seek help and assistance from professionals.

On the other hand, researchers have come up with several addiction theories and causes to clear these misconceptions. The first theory or approach dwells on the neurobiological impacts of drug addiction and it is based on biological factors. The psychological approach concentrates on individual differences and behavioral models. The sociocultural approach explains addiction based on environmental and cultural factors Wise \& Koob [6]. In this paper, a variety of different approaches that answer the question of why people become addicted to drugs will be explored in depth, to have a clear understanding of the scale of addiction 


\section{Data Collection}

To facilitate this study, data was collected primarily using secondary research techniques. Most of the data was obtained from the National Institute on Drug Abuse (NIDA) [1]. Furthermore, some scholarly articles and publications were utilized to supplement this data. Information on the addictive potential of various drugs such as heroin, nicotine, and alcohol were generated by Hall, Carter and Forlini [3] from the Scientific Research Society. Similarly, Hasin and Grant [4] obtain data about drug and alcohol dependence from the National Epidemiologic Survey on Alcohol and Related Conditions (NESARC). Likewise, National Survey on Drug Use and Health (NSDUH) was also incorporated in this research paper. Government, hospital and other private organizations' websites and portals were used to provide a more compelling medical outlook, prevalence, and addiction rates. Finally, mathematical calculations were done using the cumulative probability/frequency technique, a metaanalysis approach, and estimation method.

\section{Result}

As earlier stated, drug addiction is indeed a complicated mental condition that can arise from several environmental, biological and developmental reasons. These causative factors include peer pressure, individual biology or genetics, experimenting with drug use at an earlier age, family history, co-occurring mental states, and unprofessional medical practices among other factors Wise and Koob [6]. Most of the materials employed in this research seem to indicate that there is no straightforward way of establishing which drug between alcohol, nicotine, and opioids is more addictive than the other. In general, the issue of addiction has many gray areas when it comes to ascertaining if an individual suffers an addiction disorder, and there is no standard definition of addiction Hasin and Grant [4]. There is no consensus yet on a common definition and interpretation on addiction.
Therefore, there is no established way of measuring the scale of addiction in a substance or drug. Nevertheless, researchers and medical experts have come up with a five-factor measure of ranking drugs based on their scale of addiction. These factors include dependence, tolerance, intoxication, withdrawal, and reinforcement. Using these criteria, we can start discussing how addictive some of the illicit and legal drugs are compared with one another. The focus of this paper was on nicotine, alcohol, and opioids.

Wise and Koob's [6] definitions of these criteria were quite useful for this research. For instance, withdrawal refers to the presence and seriousness of obvious withdrawal symptoms. Tolerance entails the amount of the drug required to settle rising cravings and the level of satisfaction that is finally attained. Reinforcement, on the other hand, measures the ability of the drug to make users consume it over and over, and the level of preference compared to other drugs. Despite not having been considered an addiction measure, the level of intoxication affects addiction and increases the social and personal damage a drug brings. Finally, dependence involves the difficulty of quitting, the number of users who finally become addicted, the rate of relapse, the significance users give to the drug and the extent to which the drug continues to be used even if it is found or classified to be harmful Wise and Koob [6].

\section{Discussion}

The following comparative rating scale for alcohol, heroin, and nicotine was developed from the research conducted. The scale of addiction is between 1 to 10 . A lower score or value denotes a less serious addiction level, while a higher score denotes more serious addiction cases. Furthermore, the five addiction factors are represented using different colors as shown in the graph below. Blue denotes dependence, red denotes tolerance, green denotes withdrawal, and vibrant purple denotes intoxication while light blue denotes reinforcement (Table 1) (Figure 1).

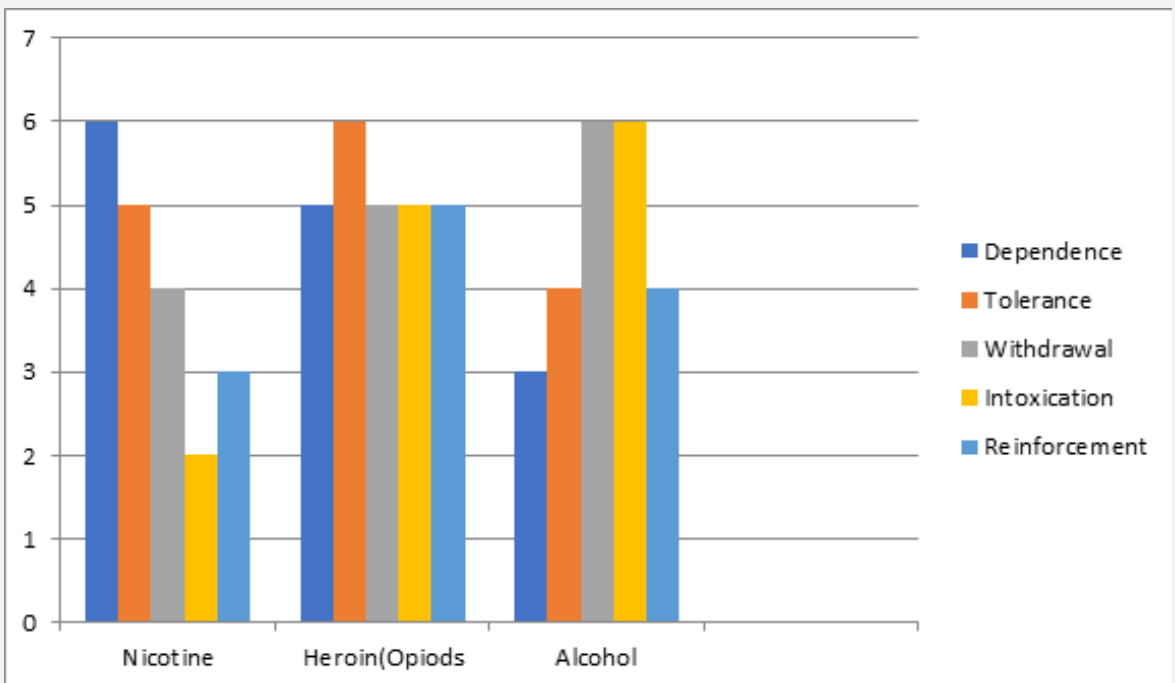

Figure 1: Comparative Rating Scale 
Table 1: Comparative rating scale.

\begin{tabular}{|c|c|c|c|}
\hline Addiction Factor & Nicotine & Heroin (Opioids) & Alcohol \\
\hline Dependence & 6 & 5 & 3 \\
\hline Tolerance & 5 & 6 & 4 \\
\hline Withdrawal & 4 & 5 & 6 \\
\hline Intoxication & 2 & 5 & 6 \\
\hline Reinforcement & 3 & 5 & 4 \\
\hline
\end{tabular}

\section{Dependence}

Data obtained from the National Council on Alcoholism and Drug Dependence shows that about 17.6 million US citizens suffer from alcohol addiction Hasin and Grant [4]. However, considering that alcohol a legal substance and socially accepted, it will be unfounded to conclude that it is the most addictive drug. Alcohol is quite hard to quit since it is easily accessible, and active marketing campaigns also contribute largely to this. Compared to nicotine and opioids (heroin), alcohol ranks the least addictive drug in this category.

\section{Tolerance}

Most people develop alcohol tolerance at a moderate rate. Even casual drinkers may find that they need a little more alcohol to get drunk compared to when they started drinking. Nevertheless, it is hard to measure tolerance because the level of intoxication is also influenced by many external factors such as what one ate that same day.

\section{Withdrawal}

Compared to heroin and nicotine, alcohol ranks the worst when considering withdrawal. In the most severe instances, alcohol withdrawal can be lethal because it produces delirium tremens that can rapidly develop to seizures and irregular heartbeat, which are sometimes deadly.

\section{Intoxication}

Before reaching a level of overdose, alcohol intoxication is very high. Furthermore, the psychological and physical impacts of alcohol intoxication are always varied and rather severe. It is always easy to tell when someone has drunk too much alcohol. Additionally, alcohol has been found to lower inhibitions, and this can lead to alcohol levels that increase the probability of addiction. On the scale of intoxication, alcohol out-performs all the other drugs Abuse [5].

\section{Reinforcement}

On this scale, alcohol is relatively lower than cocaine and heroin. Fatseas et al. [7] attest this to the fact that although alcohol intoxication is a pleasant thing, it does not generate the intensive high euphoric feelings caused by the hard drugs. However, it has a reinforcement score higher than that of nicotine because it is physically addictive.

\section{Nicotine}

\section{Dependence}

On this scale alone, nicotine is the most addictive drug compared to the rest of other common drugs, even outperforming alcohol and heroin. This is quite surprising given that it does not cause similar problems attested to alcohol and heroin. Despite the serious health risks associated with nicotine, most individuals who begin smoking tobacco end up addicted, and they it rather difficult to quit the habit totally. For instance, the report published by the Centers for Disease Control and Prevention estimates that nearly 480,000 people die annually from cigarette smoking Degenhardt et al. [2].

\section{Tolerance}

It seems that tolerance to nicotine products builds up quickly. After the first instance of using nicotine, many people tend to take it several times every day simply because it has a high dependence level. In effect, the increased rate and frequency of use of nicotine builds tolerance very quickly, thus increasing the risk of addiction. In fact, nicotine ranks only second to heroin in terms of tolerance.

\section{Withdrawal}

According to various research findings, nicotine withdrawal is more moderate when comparing to alcohol and heroin, despite being troublesome. Emotional effects such as irritability and cravings are quite prominent among nicotine users, but it is unlikely to see it confine people to bed with flu-like symptoms and pain for a week.

\section{Intoxication}

Nicotine is only associated with mild stimulant side-effects; hence its scale of intoxication is relatively mild compared to alcohol and heroin. This explains why only a sizeable number of users go back to get more.

\section{Reinforcement}

In the reinforcement scale of addiction, nicotine ranks the lowest compared to alcohol and heroin, according to data derived from Abuse [5]. This is mainly because among new users, nicotine does not generate the same kind of high euphoric feelings like alcohol and heroin. This denotes that only a small number of first-time users of nicotine become addicted because many of them do not bother to try it again. Nevertheless, this is the same reason that makes nicotine rank the highest in the dependence scale.

\section{Heroin}

\section{Dependence}

Heroin has a very high dependency rate because nearly $23 \%$ of its users have been found to become addicted to it Abuse [5]. One of the most severe problems associated with heroin is relapses, and many of people who used to take this drug and quit 
at some point in life, die from cases of overdose immediately after resuming its use. Furthermore, withdrawal symptoms coupled with this euphoric sensation cause users not to contemplate quitting. Fatseas et al. [7] outline that cravings for heroin are the most intense compared to any other drug.

\section{Tolerance}

Tolerance to heroin also builds rather quickly, hence most of its users claim that they find it hard to re-experience their first euphoric feeling once it recedes. As a result, they keep on chasing this sensation, which may take many years. Therefore, heroin is considered a very dangerous drug. After all, addicted users contemplate mixing it with other drugs to get a higher and better feeling of being high, once they develop tolerance. Therefore, the risk for overdosing is quite high among heroin users.

\section{Withdrawal}

Withdrawing from using any opioid is a terrible experience for many users even though the drug itself is not directly dangerous. Addicted users usually complain of intense malaise, relapse, terrible flu symptoms, and terrible pains. Consequently, different medications are used to treat this addiction and help the addicted people overcome these symptoms. According to Hall, Carter and Forlini [3] the success rate for overcoming this type of addiction and quitting opioids altogether is estimated at a mere level of 5-10 percent. Therefore, it is critical to offer professional assistance and medications to the addicts.

\section{Intoxication}

It is only alcohol addiction that beats heroin in terms of intoxication. Most importantly, addicts of heroin report a significant level of intoxication after experiencing the euphoria, an in most cases they will be seen nodding their heads even when the conversation is in the middle.

\section{Reinforcement}

Heroin reports a higher level of reinforcement compared to alcohol and nicotine because of the intense feeling of euphoria. Even when the drug is tested on animals, the animals will come back for more once the initial euphoric feeling fades away. In most instances, heroin creates a bingeing habit in which users crave for more once the initial feeling wears off, and this increases the risk of addiction.

\section{Conclusion}

The drug menace is becoming a thorny issue among the political, social, economic, and demographic aspects of the modern world. Different theories have been put forward to provide a deep understanding of the addiction problem. Furthermore, biological, psychological and developmental factors have been found to facilitate the rise in drug and substance abuse. However, there are varied perceptions on this issue, hence there is no standard definition or way of establishing which drug or substance is more addictive than the other.

Different scaling criteria on addiction have been developed to facilitate this work. Many scholars, experts, and scientists have agreed on using withdrawal, tolerance, dependence, intoxication, and reinforcement has measures of identifying the addictive qualities of various drugs. From the research, it was difficult, to sum up these measures and come up with a standard answer as to which drug between heroin (opioids), nicotine and alcohol is more addictive than the other. To compare the degree of addiction among different drugs should, therefore, be done using these five criteria. This creates a room for future studies and ways of generalizing the scale of addiction among various drugs. Therefore, I recommend that further efforts be directed to this.

\section{References}

1. Nora D Volkow (2014) Drugs, brains, and behavior: The science of addiction. National Institute on Drug Abuse (NIDA), USA.

2. Degenhardt L, Whiteford HA, Ferrari AJ, Baxter AJ, Charlson FJ, et al. (2013) Global burden of disease attributable to illicit drug use and dependence: findings from the Global Burden of Disease Study 2010. Lancet 382(9904): 1564-1574.

3. Hall W, Carter A, Forlini C (2015) The brain disease model of addiction: is it supported by the evidence and has it delivered on its promises. The Lancet Psychiatry 2(1): 105-110.

4. Hasin DS, Grant BF (2015) The National Epidemiologic Survey on Alcohol and Related Conditions (NESARC) Waves 1 and 2: review and summary of findings. Soc psychiatry psychiatr epidemiol 50(11): 1609-1640.

5. Abuse S (2013) Results from the 2012 National Survey on Drug Use and Health: Mental health findings. NSDUH Series H-47, HHS Publication No (SMA), Maryland, 13: 4805.

6. Wise RA, Koob GF (2014) The development and maintenance of drug addiction. Neuropsychopharmacology 39(2): 254.

7. Fatseas M, Serre F, Alexandre JM, Debrabant R, Auriacombe M, et al. (2015) Craving and substance use among patients with alcohol, tobacco, cannabis or heroin addiction: A comparison of substance-and person-specific cues. Addiction 110(6): 1035-1042. 
(C) This work is licensed under Creative

BY DOI: 10.19080/PBSIJ.2018.10.555778

\section{Your next submission with Juniper Publishers} will reach you the below assets

- Quality Editorial service

- Swift Peer Review

- Reprints availability

- E-prints Service

- Manuscript Podcast for convenient understanding

- Global attainment for your research

- Manuscript accessibility in different formats

( Pdf, E-pub, Full Text, Audio)

- Unceasing customer service

Track the below URL for one-step submission https://juniperpublishers.com/online-submission.php 